\title{
Significaciones del abuso sexual infantil intrafamiliar en contexto mapuche rural
}

\section{Meanings of domestic child sexual abuse in rural mapuche context}

Aceptación: 15 de marzo de 2010. Aprobación: 15 de junio de 2010.
Lilian Sanhueza Díaz ${ }^{1}$

Fabiola Hernando Pérez²

\begin{abstract}
RESUMEN
El presente trabajo muestra los resultados de un estudio de caso realizado en la Región de La Araucanía, con actores sociales relevantes para el mundo mapuche y familias afectadas por situaciones de abuso sexual. Se plantean los principales hallazgos, en torno a las visiones que estos actores sociales tienen respecto del abuso sexual infantil intrafamiliar, en el complejo contexto de relaciones interétnicas característico de esta región. Destaca la pérdida de mecanismos de protección propios de la cultura, el potencial rol de las autoridades tradicionales, la vulnerabilidad de la figura materna, las condiciones sociofamiliares que constituirían factores de riesgo ante situaciones de abuso sexual infantil y la valorización del rol de facilitador intercultural y de la lengua materna como dispositivo terapéutico.

Palabras clave: Mundo mapuche, relaciones interétnicas, abuso sexual infantil.

ABSTRACT

The present work shows the results of a study of case realized in the region of the Araucania, with social relevant actors for the world Mapuche and families affected by situations of sexual abuse. The principal finds appear, concerning the visions that these social actors have respect of the sexual infantile abuse, in the complex context of interethnic relations typical of this region. Emphasizes the loss of own(proper) mechanisms of protection of the culture, the potential role of the traditional authorities, the vulnerability of the mother figure, the conditions sociofamiliares that would constitute factors of risk before situations of sexual infantile abuse and the appraisement of the role of intercultural facilitator and of the mother language as therapeutic device.
\end{abstract}

Key words: World mapuche, interethnic relations, sexual infantile abuse.

Trabajadora Social, Magíster en Intervención Social, Docente Escuela de Trabajo Social. Universidad Católica de Temuco. Mail: Isanhueza@uct.cl

2 Trabajadora Social, Magíster en Intervención Social, Docente Escuela de Trabajo Social. Universidad Católica de Temuco. Mail: mafaher@uct.cl 


\section{Introducción}

A lo largo de la historia, la intervención sociofamiliar en abuso sexual ha derivado en una relación asimétrica, mediatizada por una metodología en ocasiones rígida y con un fuerte componente de control social, a partir del enfoque positivista y tecnocrático que durante décadas ha predominado en las profesiones de "lo social".

El abuso sexual infantil que ocurre en el seno de la familia, dentro de la cultura occidental, es definido como un problema social frente al cual el Estado genera una serie de políticas públicas destinadas a la prevención y sanción del delito, además de acciones llamadas de "reparación del daño". Cuando Cecilia Aguayo nos advierte acerca de la importancia de comprender las vivencias de la sociedad en la que se producen estos problemas sociales, surge la necesidad imperante de profundizar en el contexto interétnico propio de la Región de La Araucanía, la cual presenta una de las más altas tasas de población mapuche emplazada en el mundo rural. Nos recuerda Aguayo: “El problema no es solo comprender las significaciones del otro, sino que también comprender las vivencias de la sociedad en que se producen estos problemas sociales" (2006:138). El pueblo mapuche, las familias mapuche rurales, constituyen ese "otro", con quien el profesional construye el mundo significativamente en una relación cara a cara.

Lo anterior se torna doblemente relevante si asumimos que la relación profesional - "sujeto de atención" en situaciones de abuso sexual infantil ha estado connotada históricamente por altas dosis de poder, con el que el Estado embiste al profesional para ejercer, prioritariamente, control social. La relación asimétrica basada en el ejercicio del poder de parte del profesional, que mencionamos anteriormente, constituye el "caldo de cultivo" para la discriminación basada en el etnocentrismo. Los profesionales “están" en la relación "cara y cara" y son responsables en la construcción de una relación de mayor interculturalidad.

\section{Etnocidio, trauma histórico y violencia colateral}

Aguirre plantea que el Estado tiende a una coordinación centrípeta, a una unidad, que a menudo genera unicidad, buscando homogeneizar y normalizar los diferenciales étnicos a través de distintas estrategias. A partir de los distintos cuerpos legales y políticas públicas, el Estado coordina las acciones de los ciudadanos en virtud del modelo de desarrollo que persigue, en el entendido que "esta homogeneidad étnica significa para el Estado chileno estabilidad y cohesión, mientras que la multiplicidad de grupos étnicos representa tensión e inestabilidad permanente" (1997:51).

La relación entre el Estado chileno y el pueblo mapuche ha provocado a lo largo de los años un deterioro en las condiciones socioculturales de este pueblo: "la expropiación de casi todas sus tierras y recursos naturales y la consiguiente generación de minifundismo conllevarían a la creciente pauperización de gran parte de la población y a su marginación de muchos de los procesos económicos-políticos de la sociedad nacional" (Aguirre. A; 1997:260). A este respecto cabe recordar los antecedentes expuestos por el periódico El Ferrocarril y aquellos acontecimientos registrados en la "Memoria de Guerra Pacificación de la Araucanía 1887", donde es posible apreciar la devastación causada por el ejército chileno, al apropiarse de ganado, cultivos, viviendas, arrasando con todo a su paso, incluyendo las vidas humanas de los indígenas de la época, quienes eran sometidos a múltiples formas de tortura y denigración (Bengoa, 1996).

En la actualidad, se continúan empleando distintos mecanismos de etnocidio encubierto, en la medida en que se desconfirma la identidad étnica diferenciada de la alteridad, buscando la asimilación en desmedro del reconocimiento. El etnocidio se entiende como "el intento deliberado de erradicar una cultura o modo de vida de un grupo de personas (...) el etnocidio depende del uso de poder político para forzar a gente relativamente indefensa a renunciar a su CULTURA y es, por lo tanto, en situaciones coloniales en que la coerción puede ser aplicada impune- 
mente. (Barfield, 1997, citado en Fundación Legado de Esperanza, 2003:18). Si bien es cierto, el periodo colonial histórico finalizó en 1800, con la independencia de Chile, al interior de la República se ha mantenido una relación "colonialista" entre el Estado chileno y el pueblo mapuche a través del uso de la violencia crónica, física y simbólica, la burla y la desconfirmación, el desconocimiento y la desvalorización de la cosmovisión de un pueblo distinto, de parte de la sociedad no mapuche, lo que genera procesos de dolor y sufrimiento, que a nuestro juicio podrían contribuir al desarrollo de un trauma histórico. Este concepto surge del trabajo con pueblos aborígenes del Canadá y alude a las heridas emocionales y psicológicas colectivas, tanto sobre toda la vida como por sobre generaciones de individuos, resultado de una historia de etnocidio. A este respecto, diversos estudios realizados desde un marco monocultural muestran al pueblo mapuche como depositario de altos índices de deterioro en su población: índice de desarrollo humano, mortalidad, expectativas de vida, violencia intrafamiliar, resultados que son posibles de comprender a partir de este proceso de traumatización, lo que podría estar gatillando el uso de la violencia como búsqueda de reconocimiento y reivindicación, por un lado, y por otro, dichos índices a partir de los cuales se diseñan e implementan acciones estatales son el reflejo del monoculturalismo, en tanto las definiciones se basan en criterios unilaterales definidos por la sociedad no mapuche, que no incorporan la cosmovisión propia de los pueblos originarios, en general, y del pueblo mapuche, en particular.

"La violencia, así como la enfermedad y toda forma de desarmonía, aparece en contextos de pérdida de mecanismos de protección que entrega la cultura" (Servicio de Salud Araucanía Sur. Equipo mapuche de cogestión en salud; 2004:7). En el caso de la violencia intrafamiliar y particularmente del abuso sexual infantilintrafamiliar (en adelante ASII), un concepto que favorece el análisis comprensivo-relacional de esta situación es el de violencia colateral, que puede definir- se "el comportamiento vejatorio, humillante, dañino y a veces hasta violento contra un miembro de un grupo por parte de individuos del mismo grupo" (Midleton-Moz, 1999:116). Se aprecia más frecuentemente en grupos oprimidos que han quedado indefensos para contrarrestar las acciones de un grupo opresor más poderoso y que, frecuentemente, descargan su ira hacia miembros de su misma comunidad. De este modo, el ASII en contexto mapuche, así como toda expresión de violencia intrafamiliar, debe ser comprendido en este marco de relaciones interétnicas.

\section{Familia mapuche rural}

Desde un punto de vista intercultural, la familia es una forma de organización social que se estructura de acuerdo con metas consideradas legítimas en un contexto sociocultural determinado. Para Morandé (citado por Aylwin y Solar; 2002: pp. 13), la familia combina tres tipos de relaciones: la filiación, la consanguinidad y la alianza conyugal; sin embargo, el concepto de familia en el mundo mapuche no es homologable al concepto de familia del mundo no mapuche, en la medida que para el mapuche la familia históricamente ha constituido una organización social, religiosa y económica, traspasando los límites de la convivencia cotidiana.

De acuerdo a Catriquir, Durán y Quidel (2007), un concepto asociado a la idea de familia en la cosmovisión mapuche es la de reñma, que da cuenta de la idea de pariente o persona vinculada por sangre o parentesco y territorio; se reproduce a través de la compleja relación entre los rukache. El rukache es el espacio que habitan los miembros de una familia, pudiendo ser estos padres, hijos, abuelos, hermanos e incluso personas sin relación de parentesco, estos últimos llamados arimatu. Los primeros valores y mapuche kimün ${ }^{3}$ vienen del rukache. En este mismo contexto surge el concepto de füren, que alude a aquellos miembros de la familia con quienes existe mayor cercanía, se visitan frecuentemente y se comparten momentos significativos. En una perspectiva más amplia, aparece

Conocimiento del mundo mapuche. 
el concepto de lof, una forma de organización que incorpora varios reñma. Destaca el concepto kuñifaj, utilizado para aludir a una persona que ha quedado sin un vínculo afectivo directo de sus progenitores - persona carente de valores, de conocimientos sociales de mayor complejidad-, o bien la persona que, aun teniendo sus progenitores y reñma, se ha apartado a vivir sin el consentimiento, aceptación o vinculación con ellos.

De acuerdo a Catriquir, Durán y Hernández, "los matrimonios originaban los rukache $^{4}(\ldots)$, no obstante, el matrimonio puede activar o recrear reñma ${ }^{5}$, dependiendo del $a z^{6}$ de los integrantes del rukache. Así, estos dos últimos niveles constituían instancias a través de las cuales la sociedad cumplía sus fines de asociatividad (...) culturalmente ciertos valores, orientaciones ético-sociales subsumidas en el concepto $a z$ y cuyo proceso se preparaba anticipadamente por los padres (...), esta concepción se puede ilustrar con la norma a través de la cual la joven que se casa, se educa para que forme parte de otra familia y, por lo tanto, entonces reproduzca los valores, az, de esta más que los del rukache en donde nació" (2007:400).

Retomando a Quidel, vemos que la formación humana, en cuanto a los valores, es un rol que juegan los padres y abuelos, y los otros familiares se hacen cargo más bien de las necesidades básicas. Depende mucho del az en que esa familia creció. Al respecto, el mundo mapuche distingue a kümeke che como aquella familia noble, con buena formación, valores, con conocimiento mapuche, estatus económico, autovalente, en la que sus hijos(as) tiene actitud de respeto. Esta es una valoración positiva que la gente hace de otra familia. En el otro polo se encuentra wezake che, malas familias, con malos hábitos, ladrones, peleadores, con consumo de alcohol, quienes no se cuidan, son mal edu- cados, tratan mal a las personas, no respetan, no participan en ceremonias. En relación al tuwûn o territorio destacan akünche, persona que viene de afuera de la comunidad, y anünche, personas que pertenecen al lugar.

Abuso sexual infantil: aportaciones teóricas

Dentro de la cultura occidental, el abuso sexual se entiende en principio como un abuso de poder, en el que el abusador utiliza el poder físico, evolutivo ${ }^{7}$, emocional, afectivo y económico que posee para invadir el espacio sexual del otro. Carpintero, Hernández y López, (1995) indican que el abuso sexual infantil hay que definirlo a partir de dos conceptos: el de coerción y el de asimetría de edad. El uso de la fuerza, presión o engaño, es decir, el abuso de poder y la diferencia de edad, estableciéndose en cinco años el rango de diferencia, lo que permite identificar también el abuso sexual cometido por menores de edad.

En cuanto a la dinámica de familias sexualmente abusivas, los estudios de tipo occidental son múltiples y con un alto grado de profundidad. Solo por citar algunos, es posible mencionar a Malacrea y Vassalli (1990), quienes destacan la presencia de un patrón extremadamente patriarcal, con padre autoritario y dominante y madre pasiva, sometida y marginal. Existe también otro patrón de rasgos opuestos: una madre activa y segura, a menudo ausente, y un padre inmaduro, temeroso y dependiente. En ambos casos existiría una relación complementaria, con límites frágiles entre subsistemas, lo que permitiría a los hijos implicarse en funciones sustitutorias.

Perrone (1997) estudia el abuso sexual en familias desestructuradas, reconstituidas o monoparentales. Estas se caracterizan por límites rígidos al exterior y aglutinadas al

Espacio físico habitado por los miembros de una familia, constituye el lugar donde se traspasan los valores y se desarrolla la formación del che (persona). Pueden convivir personas sin vínculo de parentesco.

5 Miembros de la familia provenientes de un tronco común y que se reconocen compartiendo un mismo az (forma de ser, valores)

6 Dice relación con la esencia de la persona, su forma de ser, los valores que guían su conducta.

7 En cuanto se encuentra en una etapa del desarrollo más avanzada y por tanto cuenta con mayores herramientas para configurar las consecuencias de sus actos. 
interior, con leyes propias, donde impera el silencio y la necesidad de guardar las apariencias. El perfil del padre abusador puede ser reservado, suave y poco viril, con propuestas relacionales seudoigualitarias, o bien agresivo y violento. Perrone acuña el concepto de "hechizo" para graficar la relación complementaria y desigual, basada en la perversión del balance entre autoridad y responsabilidad.

El psiquiatra chileno Jorge Barudy (1998), uno de los más estudiados por los distintos programas que intervienen en abuso sexual en Chile y en la región, realiza un completo análisis del abuso sexual. Desde una perspectiva ecológica, analiza las dificultades del agresor para incorporar el tabú del incesto $\mathrm{y}$, desde la teoría del apego, evalúa la incidencia de las separaciones precoces y la fusión afectiva entre los padres e hijos en el establecimiento de vínculos de apego poco sanos, que sientan las bases para una relación incestuosa. Asimismo, es interesante constatar el análisis macrosistémico del fenómeno, al centrarse en el origen estructural de la violencia, originada no por la diferencia de poder, sino por el abuso de este, de parte del adulto.

Cortés y Cantón (1997) hacen referencia a los escritos de Wolfe, Wolfe y Best (1988), quienes han formulado "distintas definiciones basándose en el principio de que la conducta sexual entre un niño y un adulto siempre es inapropiada, así como el grado de relación que tiene la víctima con el agresor (abuso intra o extrafamiliar). Se parte del supuesto de que un niño dependiente, inmaduro evolutivamente, no debe implicarse en actividades sexuales que no comprende plenamente o no está capacitado para dar su consentimiento. Esta perspectiva ética tiene la ventaja de no hacer necesaria la demostración de daño resultante del abuso" (citado por Canton, J y Arboleda, M). Estos autores hacen referencia a la relación entre víctima y abusador, distinguiendo el abuso intrafamiliar o incesto como el contacto sexual entre parientes. Al respecto señalan que aun cuando la definición implica una relación genética, también se puede considerar incestuosa toda relación entre el niño y el adulto que asuma un papel de madre o de parientes, como los padrastros o los padres adoptivos.
En relación con el abuso sexual intrafamiliar, Russell (1986) elabora una definición con criterios operativos: el abuso sexual incestuoso podría ser definido como todo tipo de contacto dirigido a la explotación sexual de un familiar menor de 18 años, con independencia del grado de parentesco, siempre que la diferencia de edad supere los 5 años (citado por Linares; 2002: 64).

La terapeuta familiar Eliana Gil (1997) realiza un interesante análisis acerca de la reunificación familiar, atendiendo a las distintas corrientes que privilegian, por un lado, la defensa de las víctimas $\mathrm{y}$, por el otro, la preservación de la familia, ante los cual es fundamental el rol del Estado y su política de afrontamiento del fenómeno, distinguiendo distintos niveles y categorías de maltrato.

\section{Abuso sexual infantil intrafamiliar en otras culturas}

En países de Europa y América se han realizado múltiples estudios acerca de la transmisión transgeneracional y el significado cultural del incesto, no existiendo evidencia alguna que vincule las prácticas culturales de algún grupo étnico como facilitadores del abuso sexual. Sin embargo, es interesante constatar cómo algunos estudios muestran ciertas prácticas propias de la cultura, desplegadas para abordar situaciones de abuso sexual infantil que se producen en la comunidad y que constituirían importantes recursos protectores y de control social. Un ejemplo de lo anterior lo constituyen los activistas del territorio de Yukón, en Canadá, quienes "han desarrollado la Sentencia del Círculo, una versión actualizada de las prácticas tradicionales de sanción y curación de los pueblos aborígenes. Dentro del círculo, las víctimas de delitos, agresores, personal de servicios judiciales y sociales, y residentes de la comunidad escuchan la narración de la víctima y deliberan para determinar la mejor manera de restaurar la justicia para la víctima y la comunidad. La sentencia generalmente comprende reparación, servicio comunitario, tiempo en la cárcel, requerimiento de tratamiento y rituales comunitarios para la curación (Match Internacional Centre; 289:22). Con respecto a este último tema, cabe mencionar el estudio de Mulhern (1996 a) sobre el 
pueblo Chulupi de Paraguay. En este trabajo, el autor señala que, como todas las culturas, los Chulupi regulan la sexualidad y el incesto, aunque lo hacen de forma especialmente singular: ridiculizan en reuniones informales a las que asisten, niños y niñas, a los adultos que incurren en tales prácticas, a partir del relato del "viejo chamán", brujo que buscaba abusar sexualmente de niños y niñas y cuya conducta es repudiada por toda la comunidad que se reúne a escuchar la historia.

\section{Metodología}

Esta investigación se inscribe en un marco epistemológico constructivista, en la línea de pensamiento fenomenológico del filósofo Edmund Husserl, Alfred Shutz y los autores constructivistas Berger y Luckman. Desde esta lógica se optó por un diseño de investigación de orden cualitativo, específicamente un estudio de caso. La muestra correspondió al longko, familia kumeke che y familias afectadas por una situación de abuso sexual infantil intrafamiliar de una misma comunidad. Se trabajó en 5 comunidades ubicadas en territorio nagche ${ }^{8}$ y lafkenche . $^{2}$ Se consideró importante trabajar con comunidades de distinto territorio, en el entendido que la identidad mapuche se construye en estrecha relación con este, ya que las características del territorio definen en gran medida la relación con el mundo material e inmaterial.

\section{Acceso a la muestra}

1. Dada la sensibilidad de la temática y la confidencialidad con que se maneja la identidad de las familias afectadas por estos hechos, se informó y solicitó apoyo a la Fiscalía Regional de Temuco desde la Unidad de Atención a Víctimas y Testigos y al Centro de Atención Integral a Víctimas de Delitos Violentos, dependiente de la Corporación de Asistencia Judicial Región del Biobío, los cuales, considerando relevante el estudio, aceptaron entregar los antecedentes para contactar a las familias afectadas, a través de las profesionales a cargo y con los resguardos éticos correspondientes.

2. Una vez ubicados los lof a los que pertenecían las familias afectadas, se procedió a revisar documentación pública de la Corporación Nacional de Desarrollo Indígena CONADI. Cabe destacar que existe escasa información acerca de las autoridades tradicionales existentes en los lof, puesto que los datos versan acerca de las directivas de organizaciones funcionales e inclusive de la comunidad, no así de autoridades tradicionales.

3. Una vez llegados al lof se realiza la primera entrevista al longko, con el objeto de presentar el estudio y solicitar su autorización para realizarlo. Así también se plantea que nos recomiende una familia reconocida y valorada socialmente (kumeke che) para participar en el estudio.

Técnicas e instrumentos de recolección de información

Siguiendo la lógica protocolar del Pentukun $^{10} \mathrm{y}$, de acuerdo con lo sugerido por el asesor metodológico docente José Quidel Lincoleo, se construyó una entrevista semiestructurada, sobre la base de tres temas centrales:

1. Tuwün y küpan (territorio y linaje).

2. Significaciones de la niñez.

3. Significaciones del abuso sexual infantil intrafamiliar.

En este artículo se revisarán los principales hallazgos relacionados con el tema central $N^{\circ} 3$ Significaciones del abuso sexual infantil intrafamiliar.

Para asegurar la pertinencia de la investigación, se contó con tres facilitadores interculturales, personas mapuche hablantes

Corresponde al territorio ubicado en la zona del valle. Corresponde al territorio ubicado en la zona costera.

10 Saludo protocolar propio de la cultura mapuche, que consiste en una introducción al tema central que motiva la visita o entrevista a una familia. En dicha introducción se consulta al entrevistado por aspectos de preocupación cotidiana: situación del lof che, aspectos de salud, estado de las siembras y cosechas entre otros. 
de mapuzugun, quienes apoyaron la aplicación de la entrevista en profundidad. Durante el proceso de análisis de la información se utilizó el software Atlas Ti.

\section{Resultados}

\section{Significaciones del ASIl para los longkos}

En cuanto al abuso sexual, se plantea que los conceptos nentukar ${ }^{11}$, nentukagun, serían en mapuzugun los que traducirían esta práctica y, al igual que en la concepción occidental, aparece la coerción y el uso del poder o sometimiento de la víctima como una característica de la relación. En torno a las causas que pueden provocar estos hechos, en la familia se plantean algunas sobrenaturales "a lo mejor le entró el demonio, le entró wekufe" (P4:Longko 4); sin embargo, de manera reiterada se alude a la importancia de la familia de origen o küpan (linaje) pertenecer a una wezake che sería una probable causa "viene también por la herencia de esa persona, porque la herencia es mala, también tiene que salir heredero malo" (P3: Longko 3); e igualmente vinculada al consumo excesivo de alcohol "la enseñanza está en la casa porque si en un hogar hay una familia que viven peleando, que viven tomando o que tienen cantina que llega uno y otro y tienen niños entonces, ahí viene eso" (P5: Longko 2). Estos problemas familiares aparecen vinculados a acciones estatales que han contribuido a la desarticulación de estructuras y modos de constitución del reñma (familia) y lofche "cuando pasó la mensura acá en la comunidad había queda'o afuera nuestro guiñatuwe, y en nuestro cementerio de la comunidad, había pasado para DIGEDER ${ }^{12}$ " (P1: Longko 1); "la persona ahí de la otra comunidad no querían que pasaran ${ }^{13}$ pero igual pasó por la comunidad, (...) igual sacaron osamenta (...) atropello... porque no respeta y solamente quiere adelanto" (P3: Longko 3).

Por otro lado, en la relación pueblo mapuche-Estado se ha deslegitimado la ins- titucionalidad propia de este pueblo y, por tanto, sus autoridades tradicionales no son consideradas como actores relevantes frente a problemáticas como el ASII "la autoridad mapuche poco lo respetan, imagínese uno puede decir algo, a uno lo pueden llegar a pegar porque la verdadera autoridad es la ley, la ley chilena (...) uno como autoridad, dar cuenta a la justicia igual,(...) pero uno como autoridad mapuche podría darle un castigo, nunca mas vai a volver, así una cosa, eso podría hacer la autoridad mapuche" (P5; Longko 5). Ello se visualiza en el desconocimiento que estos tiene acerca de las situaciones que han ocurrido en sus territorios “...ojalá que nunca suceda también, ojalá que en otra parte donde a pasa'o, ojalá que deje de pasar eso también, que cosa más grave yo creo, en la vida para mi cosa muy grave" (P1: Longko 1), "pero siempre tiene que saber el longko a quien le pasó eso, porque si no sabiendo, él no puede hacer nada" (P2: Longko 2.); de este modo se constata un estado de negación al posible rol que el longko puede asumir, tanto al interior del lofche como en un trabajo articulado con la institucionalidad estatal.

A este respecto, destaca la necesidad de un reconocimiento de las autoridades tradicionales, en tanto aportan desde la cosmovisión propia de un pueblo a la comprensión de este tipo de situaciones, así como la necesidad de reconstruir los dispositivos de control social y sanción propios de la cultura, que a través de los procesos de colonización y dominación se han ido perdiendo. Se percibe en los longkos una importante disposición para abordar en conjunto con la institucionalidad del Estado chileno, las situaciones de abuso sexual infantil intrafamiliar que surjan en el lof che "que comete ese falta ese delito la justicia tienen que actuar con ello así como actúa la justicia nosotros como mapuche, tenemos que apoyar ese idea que la justicia ... que sea mano dura que comete esa persona" ( $P$ 1: Entrevista Longko 1); “...estaría bueno también sacar una ley así... que trabajemos juntos... porque nos reunimos en comunidad

\footnotetext{
11 Tomar a la fuerza.

12 Dirección General de Deportes. Organismo gubernamental encargado de administrar las políticas públicas de estimulación del deporte en Chile; entre sus funciones está la construcción de espacios para la práctica deportiva.

13 Haciendo referencia a la carretera (bye pass) que atravesó una comunidad indígena en el sector de Padre las Casas.
} 
se juntan como cuarenta personas en reuniones general... entonces con asistente social que tomen apunte y que sean asistente social que entiendan (...)... ahí hablar la lengua mapuche... se está perdiendo... nosotros tenemos que defenderlo" (P 3:Longko 3). Respecto al rol de la machi en este tipo de situaciones, los longkos plantean "la función como machi, ella puede hacerle remedio a la gente mejorarla a la gente que está enferma" (P4: Longko 4); "la machi (...) también tiene medicina arreglada de sexualidad" (P5: Longko 5); por lo cual ambos cumplirían funciones complementarias.

Siguiendo con el rol de autoridad sociopolítica del longko, destaca el destierro como sanción propuesta por uno de ellos y la crítica a la ineficacia de la acción estatal orientada a la sanción y superación de este tipo de situaciones "que se fuera para otro lado, ahí ya nunca más se haría, porque ya.... si voy hacer esto tengo que pensar de que me van a echar, hay puede haber una percepción de no hacerlo... ya sé que si hago algo me voy a ir preso..." (P 5: Entrevista Longko 5); "dejar la familia claro... ahí noooo... ahí es triste... mismos familiares, aunque sea el más malo, nunca yo creo, que va a dejar de sentir su familia" ( $P$ 5: Entrevista Longko 5).

\section{Significaciones del ASII para las kumeke che}

Respecto del abuso sexual infantil intrafamiliar, las kumeke che señalan desconocer la existencia de este tipo de situaciones, pero, en caso de suceder, consideran que el rol de la comunidad es apoyar a la víctima a pesar de que ello signifique tener problemas con el agresor. "Yo creo que la comunida' debiera reaccionar en protección de los niños o sea tomar medias o algo así, pero no se hace quizás también por el mismo temor de no tener problemas con la persona"(P5: Kumeke che 5).

En este sentido, manifiestan que las autoridades tradicionales son muy importantes para apoyar a la víctima del delito y señalan que no hay que dejar solo al longko en su labor, que el lofche debe participar en la decisión y las acciones que se determinen para enfrentar el fenómeno, y le reconocen a este su función de velar por la unidad del lofche "pero si esto hubiera pasa'o algo se haría si $p u$ '. No seee, conversarlo con el longko y no dejarlo solo, porque primero la unión, esto es importante pa' una comunida" " (P2: Kumeke che 2), "digamos, ellos deberían como lonko, como machi, como autoridades de la comunidad son los que deberían tomar con más fuerza esto, supongamos apoyar más o dar a conocer" (P5: Kumeke che 5), También expresan diferencias entre las funciones de la Machi y la labor del longko. A ella la visualizan en su proceso de sanación dirigida tanto a la víctima como al agresor, para superar la situación vivenciada. "Ayudarlo y sanarlo" (P1: Kumeke che 1). Por otra parte, señalan que los vínculos de parentesco en el lof pueden tener una doble función que se contrapone: una tiene que ver con la acogida y la otra con impedir la denuncia de los hechos, generando un conflicto de lealtades "en comprensión, trabajo, apoyo, entenderse, ayudar si necesita una ayuda" (P1: Kumeke che 1), "además que aquí todos son familia, entonces la comunidad reacciona pero de forma negativa, ocultando todo, porque todos son familia" (P5: Kumeke che 5).

Las Kumeke che señalan que los agresores provienen de wezake che, familias malas, que no entregan consejos ni valores a sus hijos, que tendrían malos pensamientos, y los factores asociados al delito son el abuso del alcohol y la posible venganza de parte del agresor "Pasaron y están pasando por esta razón y producto de que este joven tiene una familia y (...) detrás de él hubo una mamá alcohólica que vivió esa vida igual y ahora él sigue con la misma rutina" (P5: Kumeke che 5); "más por hacer sufrir a la familia una venganza (...), porque esto sucede entre familiares, aunque no sean familiar tan directa siempre hay un vínculo" (P4: Kumeke che 4). Al respecto, las kumeke che reconocen que la escasez de tierra constituye un aspectos desestructurador y de tensión para las familias mapuche "la tierra se fue haciendo poca, no se podía sembrar, solo pa' comer, después nosotros nos fuimos pa' la Argentina con mis hermanos, todavía hay uno por allá" (P2: Kumeke che 2); "que los hijos no puedan quedarse acá en el campo, es triste, el poco terreno que se tiene acá no se puede hacer, no se puede trabajar la tierra, puro terrenitos chicos, nada más" (P2: Kumeke che 2). 
Las Kumeke che resaltan que en el we kuyfi ${ }^{14}$ en la comunidad se sancionaba drásticamente a quien dañaba a un niño/a y hoy día la legislación sería muy permisiva con este tipo de situaciones "le voy a explicar un poco lo que decía mi viejo, decían que lo quemaban a la persona, la rodeaban con fuego" (P 1: Kumeke che 1), "le dan un minuto de importancia, pero la cosa ya pasó, yo creo que da igual no ma', yo creo que por eso suceden cosas, si ellos fueran más fuerte, le dieran un castigo más fuerte, así como que quede encerrado de por vida, eso sería lo lógico pero nunca lo van hacer" ( $P$ 4: Kumeke che 4);

\section{Significaciones del ASII para las familias afectadas}

Los significados del abuso sexual infantil intrafamiliar en las familias afectadas están relacionados principalmente con la vivencia del mismo, por el dolor que ha implicado para la familia enfrentar una situación de desequilibrio tan devastadora. Las madres lo viven con un sufrimiento desgarrador, de mucha tristeza, pena, vergüenza, soledad, rabia y, en un caso particular, la madre desculpabiliza al agresor, dado que este es su hijo. En prácticamente todas las situaciones abusivas, las madres viven muy solas todo el proceso, ya sea porque la familia extensa paterna a la que ahora pertenecen es considerada wezake che "Tienen envidia, me tienen de mala, se enojan porque yo no comparto con ellos, no lo asisto, no lo visito, así son mi familia... mala gente son, mi familia son mala gente" (P1: Madre S), "me hubiera gustado que me ayudaran, pero ellos no quisieron meterse en problemas, también me dijeron que había llegado en muy mala familia, tan mala suerte tuviste, estos son así están acostumbrados, nunca te van a dejar tranquila me dijeron" (P2. Madre F), "crecieron algunos, empezaron a tomar trago a los 10 años y siguen hasta el día de hoy, van a llegar a viejos, no se casan no tienen un hogar" (P3: Madre C), y no cuentan con su familia de origen como red de apoyo. Por otra parte, el sentimiento de vergüenza y dolor incide en la mantención del secreto "un año guardé este secreto sola, me cerré, no supe qué hacer no encontré salida, por eso solamente me encerré... como yo sin madre... me cerré" (P5: Madre G); "No, a nadie le avisé, calladita andaba, cuando me venían a citar los carabineros, íbamos, yo sola sabía para qué era, tienen que ir tal parte me decían" (P4: Madre A).

En los casos donde la madre se había trasladado a vivir en el territorio de su pareja, la familia extensa del varón (a la cual pertenece el agresor) suele no ser un apoyo para la víctima, por el contrario, ejercen medidas coercitivas para que no se denuncie el abuso, para que el niño/a se retracte, "le dije a mi suegra, tu hijo le hizo daño a mi niñita, yo sola lo sorprendí, haciéndole tocaciones en sus piernas, pecho, eso hizo tu hijo le dije, en eso mi suegra me dijo, no le digas a tu marido porque si le dices va a matar a tu hermano me dijo, tienes que quedarte callada,.. yo como voy a callar, pensé, pensé, lloré..." ( $P$ 5: Madre G;), "tienen varios tíos si alguno de ellos supiera por ahí, me vendrían a reclamar yo creo, también está mi suegra y mi suegro, vive todavía, ellos vendrían aquí en mi casa a regañarme, pienso yo" (P4: Madre A); solo en una situación la familia extensa realizó la denuncia del delito, sin embargo corresponde a un miembro de su familia de origen con quien la madre nunca perdió contacto: " $m i$ abuelo mío llamó a los carabinero de Puerto Domínguez y me vinieron a buscar a mi hija y a mí en la misma casa" (P1: Madre). Cuando el agresor pertenece a la línea paterna y la familia afectada reside en la tierra de los ancestros de este, la familia extensa paterna se siente con la atribución de amenazar a la víctima y su familia, existiendo además de la agresión sexual un conflicto por la tierra "un día vino a pararse aquí en el corral con un cuchillo, tienes que salir de aquí, desarmar tu casa, yo mando aquí, dijo, mañana mismo tienes que salir, yo no quiero niños chicos, dijo"(P2: Madre F). Así también, las madres refieren no sentir apoyo de parte del lofche "yo no me meto por ningún lao pu, por el accidente que le pasó a mi hija, ahora toda la gente se fue en contra mía, no me miran aho-

14 Tiempo pasado del que se tiene recuerdo. 
ra nada" (P1: Madre S), "nadie hace demanda, nadie dice nada... hablan entre ellos, no llegan muchas veces a saberse las autoridades" (P3: Madre C); sin embargo, refieren el deseo de contar con apoyo "yo por ejemplo, quisiera que me vinieran a ver para que me levanten" (P2: Madre F).

Se suma a la situación el hecho de que las familias mapuche rurales cuentan con escasos recursos económicos, por lo que el contacto con la familia de origen materna que habita en otro territorio se restringe. Así también, tienen muchas dificultades económicas para acompañar a sus hijos(as) a entrevistas, terapia o a los procedimientos judiciales: "cuando me pongo a pensar me da mucha pena, me pongo a llorar sola en la noche, tanto que me hicieron sufrir, no encontraba ni pasaje para viajar, no me quedaba gallinas ni gansos, los vendí todo para tener pasaje para la micro, ni me compraban" (P2: Madre S). Lo anterior es particularmente complejo, puesto que desde la racionalidad occidental se evalúa el vínculo y compromiso de la figura protectora (habitualmente madre y familia extensa), de acuerdo a su participación en el proceso: "en el juzga'o me dijeron: mientras más vea a su hija, más luego se va recuperar su hija me dijeron, porque si usted no va, se deja estar, no tiene cariño con su hija me dijeron, pero nunca la dejé solita" (P1: Madre S), participación que, como vimos, se ve fuertemente restringida por factores económicos y culturales, en este último caso, por el "analfabetismo intercultural" 15 de que adolecen tanto los procesos de intervención como los profesionales que abordan este tipo de situaciones.

En este mismo sentido, un elemento muy valorado por las familias afectadas en la aplicación de la entrevista fue el poder conversar sobre un tema doloroso y delicado en su propia lengua y con una persona de su pueblo. Los profundos y particulares significados que otorga la lengua a la compresión de un hecho tan doloroso puede considerarse inclusive un dispositivo terapéutico en la medida que facilita la expresión del dolor emocional. "Sale mejor la conversación entre mapuches pu" (P 2: Madre) "estas señoras llegaron a verme el otro día y me dijeron que me iban a traer una persona de mi raza para que conversáramos; ya le dije yo... entre mapuche se entiende mejor uno pu, va bien la conversación. Con no mapuche no es lo mismo" (P 5: Madre).

El Küpan está mediatizado por las relaciones de parentesco y las fuerzas que se generan en el lofche dependiendo del az (características, cualidades y personalidad) de las personas (che) que lo componen. Así la condición de kuñifaj, se repite en las historias familiares de las madres de víctimas de abuso sexual intrafamiliar y debiera ser considerado al momento de diseñar e implementar un proceso de acción profesional con pertinencia cultural: "mi papá me pegaba mucho, ante no había los carabinero, no había psicólogo, no había asistente social, mi mamá me dejaba botau, me dejaba solita mi mamá, se ponía a tomar todo el día" ( $P$ 1: Madre 1); "me he ido a la casa de mi mamá, he estado un tiempo allá, pero allá también me echan, y me vengo, ando trayendo a mis hijos, así he andado" (P 2: Madre S) "no, no tengo papá, fui desacreditada por mi abuela por ser coilla, porque lo encontraban pillo, no sé ... momento malo que he pasado, mucho problema abuso, maltrato, discriminación, todo eso (P 3: Madre C) "yo crecí con mi abuela, cuando era niña me dieron, ahí me crié, conocí a mi marido, nos casamos y ahora soy de acá, no conozco cariño de madre, cariño de padre" (P 5: Madre G); "Porque a mí me entregaron así por así pu, mamita, a me dieron porque era enferma, tenía ataque de epilepsia, cuando era guagua, dicen que me daba ataque cuatro veces al día, por eso me entregaron donde mi abuela, ella me hicieron remedio, me llevaron donde una machi jovencita, dice mi abuela" (P 5: Madre $G)$. Finalmente, el territorio o tüwun aparece como un elemento central en la configuración de la identidad mapuche, aspecto que debe ser considerado en los procesos de análisis y

15 Concepto acuñado por el filósofo Raúl Fornet Betancourt, en torno a nuestra situación de desconocimiento que tenemos sobre otras culturas y formas de vida y por tanto la arbitrariedad que ello conlleva en nuestra relación con la "otredad". 
acción profesional: “mi mamá era de acá: mi papá es de cajón, pero ellos se separaron, mi papá se fue a otro lado, a la casa de otra mujer, anükompuy, por eso nosotros casi nos criamos solo con la mamá, pasamos por varias necesidades (P5: Madre $G$ ), es el campo de mi papá, mi marido no tiene campo, de todo el tiempo que estuvimos casados, nunca le dijeron: trabaja, siembra un saco de trigo, no le decían. Yo en el campo de mi papá sembrábamos, ahí trabajábamos los dos (P4: Madre A).

\section{Conclusiones}

El abuso sexual infantil intrafamiliar en contexto mapuche rural es una problemática que se inscribe en un contexto de relaciones interétnicas, que deben estar a la base de su análisis y comprensión, por lo cual conocer la visión de los actores sociales constituye el primer paso para avanzar en el reconocimiento de esta situación. Al respecto destacamos los siguientes hallazgos:

küpan (linaje) y tuwün (territorio) son dos elementos muy relevantes para "el buen vivir" del pueblo mapuche. Las actuales condiciones de deterioro del territorio afectan las relaciones del lofche y del reñma, por tanto la violencia y el maltrato pueden surgir con mayor fuerza, en la medida que existe un desequilibrio en la relación del mapuche con la naturaleza. Se aprecia un debilitamiento de la vida espiritual del mundo mapuche; influenciado por distintos credos religiosos occidentales que coartan la participación en ceremoniales propios de este pueblo y a través de los cuales se fortalece la identidad colectiva y cultural. Esta situación puede comprenderse a partir del proceso de etnocidio sistemático vivido desde el proceso de pacificación de La Araucanía, entrega de títulos de merced, reubicación de los mapuche en comunidades que no constituían las formas tradicionales de organización, políticas públicas integracionistas, entre otras acciones estatales, que favorecieron la pérdida de mecanismos de control social propios de la cultura.

El vínculo con la familia de origen y el lofche es tremendamente valorado, al punto que se plantea de parte de uno de los longkos, el destierro como la más severa de las sanciones posible; sin embargo, al no existir un reconocimiento del parte del Estado chileno, respecto de los diferenciales culturales y una validación de las autoridades tradicionales, se dificulta un diálogo genuino, tendiente a un trabajo de prevención y resignificación efectivamente articulado y con pertinencia cultural.

Para las madres de hijos(as) que han sido víctimas de abuso sexual infantil intrafamiliar de parte de un miembro de la familia extensa de su pareja, la situación se torna muy compleja y se vive con muchísima soledad. Lo anterior, sobre todo en los casos en que se ha respetado la patrilocalidad, y es la madre quien pasa a formar parte del lofche de su pareja, y por tanto del linaje de este, la mujer queda expuesta a posibles amenazas y coerción para evitar denunciar la situación. La actual situación de pobreza en que se encuentran las familias por la usurpación territorial dificulta que la madre mantenga los vínculos con la familia de origen, ya que, al no existir recursos económicos, se restringen las visitas de parte de la familia de origen y los encuentros entre familias, establecidos culturalmente y que permitían regular la situación de vulnerabilidad en que actualmente se encuentran las madres cuando el agresor es miembro de la familia del padre. Así, cuando los lazos se han mantenido, este vínculo es clave. En todos los casos estudiados, el agresor pertenecía a la familia extensa del padre, lo cual es significativo si consideramos que la violencia es de tipo colateral (hacia miembros del mismo grupo) y que existen serios conflictos internos por la propiedad de la tierra, pues, en la medida que la familia crece, la proporción de tierra disponible va disminuyendo ostensiblemente.

Algunas condiciones que se asocian a esta situación son las de kuñifaj (persona sola, sin referente significativo que realice el proceso de formación valórica) Varias de las madres de hijos(as) víctimas de ASII reconocen tener esta condición. 
Así también aquellos anükon (que viene de otro territorio, cuyo linaje no pertenece a ese (ugar) o anünkompuy, de lo que se desprende la relevancia del territorio como elemento configurador de la identidad personal y colectiva. Esta cuestión debiera ser considerada en la acción profesional con familias en este tipo de situaciones.

En términos generales, el abuso sexual infantil es significado como un hecho tremendamente doloroso, que genera mucha verguienza, y en el que los adultos en condiciones de proteger (principalmente madres) se sienten muy solos. En este sentido, la participación de una facilitadora intercultural mapuche que manejaba el uso del mapuzugun fue relevado por las familias afectadas como una oportunidad de conversar de un tema tan doloroso en su propia lengua y con una persona de su pueblo. Así también fue posible observar en las entrevistas la fluidez y emotividad que surge en las madres al hablar de la situación abusiva en mapuzugun, toda vez que existen conceptos propios de la cultura que no tienen un homólogo en la lengua española $y$, por tanto, el uso de una segunda lengua limita la expresión de emociones. En este sentido, es que postulamos el uso de la lengua nativa como un dispositivo terapéutico relevante a considerar en el proceso de resignificación con las familias afectadas en donde se habla mapuzugun.

Existe una crítica generalizada a la actual legislación, en cuanto se basa en la penalidad y no en la resignificación de lo sucedido y, por tanto, la restitución del equilibrio quebrantado con esta transgresión. En general, no se aprecia registro de antiguos mecanismos de sanción y control social en esta materia, exceptuando una familia kumeke che que plantea haber oído que antiguamente una persona que cometía esta transgresión podía ser quemada viva por el lofche. Así, es posible apreciar una actitud de absoluto repudio al agresor, sin embargo, consideramos que los procesos de asimilación y etnocidio han dificultado la reproducción de mecanismos de control y sanción propios de la cultura, por lo que se estima necesario y urgente un trabajo de reconstrucción de la memoria histórica con kimches (sabios) y ancianos, que permitan recuperar y actualizar estos dispositivos.

\section{Bibliografía}

AGUAYO, C. (2006). Las Profesiones Modernas. Dilemas del Conocimiento y del Poder. Santiago: Ediciones Universidad Tecnológica Metropolitana.

AGUIRRE, A. (1997). Cultura e Identidad Cultural. Santiago: Editorial Bardenas.

AYLWIN, \& SOLAR. (2002). Trabajo Social Familiar. Santiago: Editorial Universidad Católica de Chile.

BARUDY, J. (1998). El Dolor Invisible de la Infancia. Una Lectura Ecosistémica del Maltrato Infantil. Barcelona: Editorial Paidós.

BENGOA, J. (1996). Historia del Pueblo Mapuche (Siglo XIX y XX). Santiago: Ediciones Sur. Colección de Estudios Históricos.

BENGOA, J. (1987). Historia del Pueblo Mapuche. Santiago: Editorial Sur.

CANTON, J., \& CORTÉS, M. (1997). Malos Tratos y Abuso Sexual Infantil. Madrid: Siglo XXI de España Editores.

CARPINTERO, E., HERNÁNDEZ, A., \& LÓPEZ, F. (1995). Los Abusos Sexuales de Menores: Concepto, Prevalencia y Efectos. Madrid: Editorial Infancia y Aprendizaje.

CATRIQUIR, DURÁN, \& HERNÁNDEZ. (2007). Patrimonio Cultural Mapuche. Temuco: Ediciones UCTemuco.

FORNET, R. (2000). Interculturalidad y Globalización. San José, Costa Rica: Editorial DEI.

GIL, E. (1997). Tratamiento Sistémico de la Familia que Abusa. Buenos Aires: Ediciones Granica S.A.

IBACACHE. (2001). Relaciones Familiares en el Mundo Mapuche ¿Armonía o Equilibrio? Investigación del Equipo Mapuche de Cogestión en Salud, Servicio de Salud Arauncanía Sur, Temuco. 


\section{UNIVERSIDAD CATÓLICA DE TEMUCO}

LARRAÍN, J. (2000). Identidad y Modernidad en América Latina. México D.F: Océnao.

LINARES, J. (2002). Del Abuso y Otros Desmanes: Editorial Paidós Ibérica

MALCREA, M., \& VASALLI, A. (1990). Segreti di Famiglia. L'Intervento nei Casi de Incesto. Milan: Editorial Paidós.

MATCH INTERNACIONAL CENTRE. (1994). The Circle of Healing: Aboriginal women organizing in Canadá. In Davies, M. Women and
Violence: Realities and Responses Arround de World. Canadá: London Zed Books Ltd.

MULHERN, S. (1996). L'Inceste: Histoire d'en rire. Cahiers Critiques de Therapie Familiale et de Practiques de Reseaux. Francia.

PERRONE, R. (1997). Violencia y Abusos Sexuales en la Familia. Un Abordaje Sistémico y Comunicacional. Buenos Aires: Editorial Paidós.

SCHUTZ, A. (1993). La Construcción Significativa del Mundo Social. Barcelona: Paidós. 